\title{
Age and the perception of pain
}

\section{DIANA R. HASLAM, University of Bristol, England}

An experiment was carried out to determine the relationship between age and pain threshold in a group of Ss aged 5 to 18 years. The relationship was found to be significant, and it is suggested that perception of pain is a declining function from an early age throughout life.

A number of studies have been carried out on the relationship between age and the perception of pain. Most of these, however, are devoted to the study of adult Ss, and in those studies in which children were included they were grouped with older Ss (e.g., Chapman \& Jones, 1944; Schludermann \& Zubek, 1962).

Although it is assumed that there is a relationship between pain perception and age in children such that the younger the child the lower his pain threshold, it appears that no systematic study has been carried out to determine the size of the relationship. Accordingly, it was decided to assess the pain thresholds of school children aged 5 to 18 years and to relate their ages to the threshold values found.

\section{METHOD}

For practical reasons pressure pain was selected as the most suitable type of experimental pain for a study with children, and a pressure algometer similar to that used by Keele (1954) and by Merskey \& Spear (1964) was used. Details of this apparatus can be seen elsewhere (Haslam, 1967), but essentially it is a metal box containing a spring which is attached to a plunger.

The instrument was applied horizontally to the tibia, and pressure was increased at a constant rate of approximately $1 \mathrm{~kg} / \mathrm{sec}$. Children aged 12 and older were told that they would feel increasing pressure which would become painful, and they were asked to report as soon as the feeling of pressure tumed into one of pain. The test was repeated on different areas of the tibia until consistent readings were obtained on three occasions. For half the Ss the right leg was used, and for the other half, the left.

The procedure was slightly different for the younger children. The word "pain" was omitted from the instructions in order to avoid undue alarm. Instead it was explained that the pressure on the leg would "begin to hurt a little," and they were asked to report as soon as the "hurting feeling" began. As the concept of pain threshold was rather difficult to explain to the younger children an attempt was made to obtain reliable results by assessing pain threshold on both legs. Measurements were repeated until consistent readings were obtained twice on each leg. 1

The experiment was carried out in school in a room set aside for the purpose. Each child was tested alone.

One hundred and fifteen children, approximately half of whom were male, were drawn from two primary schools and a comprehensive school, at in Bristol. The primary schools together covered a wide range of socioeconomic backgrounds, as also did the comprehensive school. Figure 1 shows the age and sex distribution of the children.

\section{RESULTS AND DISCUSSION}

Spearman's ranking method was used and a rho correlation of +0.66 was found between age and pain threshold values. This is significant at the 0.001 level of confidence, and it indicates that the younger the child, the lower is his pain threshold.

With regard to earlier work on the relationship between age and pain threshold, Chapman \& Jones (1944), in a study of heat-pain, reported that "pain-perception decreased with age," but these authors did not carry out a statistical analysis of their results. However, using the data they give it was calculated that the group aged 10 to 22 years had a significantly lower mean pain threshold $\left(289 \mathrm{mc} / \mathrm{sec} / \mathrm{cm}^{2}\right)$ than the group aged 23 to $44\left(324 \mathrm{mc} / \mathrm{sec} / \mathrm{cm}^{2}\right)$. The mean pain threshold for this group, however, was just not significantly lower than that for the group aged 45 to 85 years $\left(347 \mathrm{mc} / \mathrm{sec} / \mathrm{cm}^{2} ;\right.$ SE of difference $=11.99$; difference between means $=23$ ).

Other Es who have found that pain threshold increased with age include Sherman \& Robillard (1960), who used two groups of Ss, one aged 20 to 30 and the other 65 to 97 ; Schludermann \& Zubek (1962) who used four groups of male Ss aged 12 to 29,30 to 44,45 to 59 , and 60 to 83 years; and Hall \& Stride (1953) who used 256 neurotic and depressive patients aged 18 to 70 years. Wolff \& Jarvik (1965) reported a similar finding for men but not for women. Although there is some evidence to the contrary (e.g., Sherman, 1943; Hardy, Wolff, \& Goodell, 1952), the consensus seems to be that the ability to perceive pain does diminish with age. A similar view is held by clinicians.

The present results indicate that pain threshold increases between the ages of 5 and 18 years. In view of this finding and the evidence given above it seems reasonable to conclude that perception of pain is a declining function from a very early age.

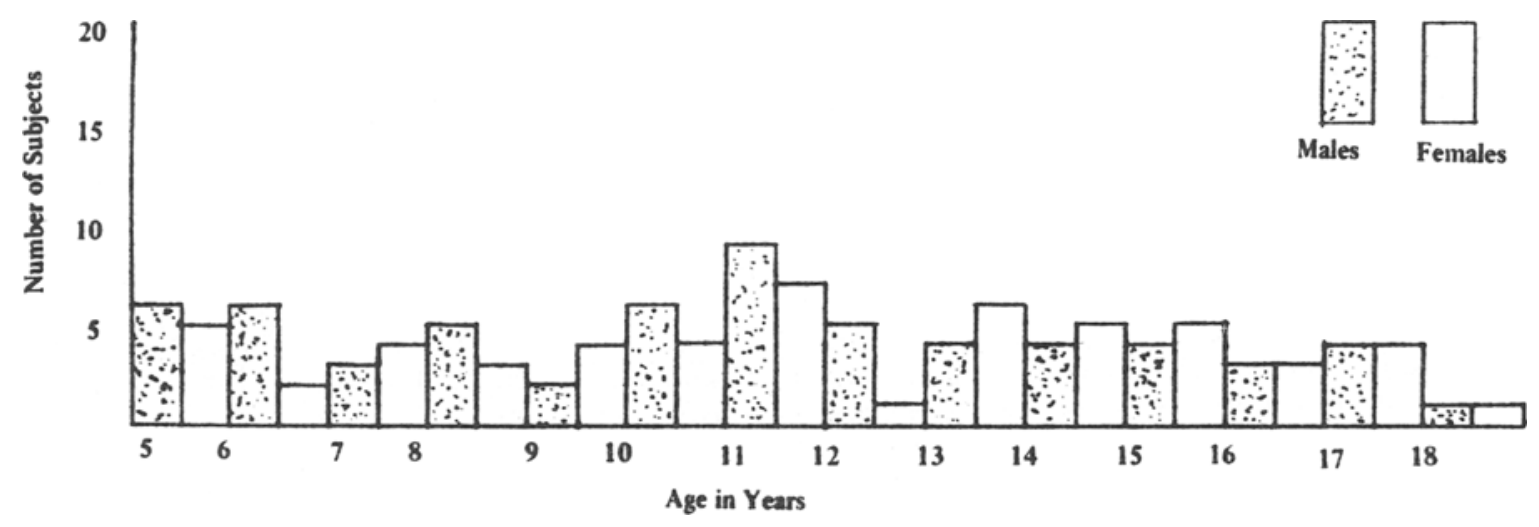

Fig. 1. Number of $S$ in each age group. 


\section{REFERENCES}

CHAPMAN, W. P., \& JONES, C. M. Variations in cutaneous and visceral pain sensitivity in normal subjects. Journal of Clinical Investigation, $1944,23,81-91$.

HALL, K. R. L., STRIDE, E. The varying response to pain in poychiatric disorders: A study in abnormal psychology. British Journal of Medical Psychology, 1954, 27, 48-60.

HASLAM, D. R. Heat pain and pressure pain. Psychonomic Science, $1967,9,567-568$

HARDY, J. D., WOLFF, H. G., GOODELL, H. Pain sensations and reactions. Baltimore: The Williams and Wikins Company, 1952.

KEELE, K. D. The pressure alsometer. Lancet, 1954, 1, 636-639.

MERSKEY, H., SPEAR, F. G. The refiability of the pressure algometer. British Journal of Social \& Clinical Psychology, 1964, 3, $130-136$.
SCHLUDER IIAN E \& ZUBEK, $\mathrm{P}$. Effect ot age on pain sensitivity Perceptual \& Motor Skills, 1962, 14, 295-301.

SHERMAN, E. D. Sensitivity to pain. Canadian Medical Association Journal, 1943, 48, 437-44I.

SHERMAN, E. D.. ROBILLARD. E. Sensitivity to pain in the aged Canadian Medical Association Joumal, 1960. 83, 944-947.

WOLFF, B. B., \& JARVIK, M. E. Quantitative measures of deep somatic pain: Further studies with hypertonic saline. Clinical Science, 1965 $28,53-56$.

NOTE

I. In order to test the reliability of this method when used with children, a test-retest procedure was carried out on 12 hospitalized children. A tho value of +0.79 was found, which is significant at the 0.02 level of confidence.

\section{Backward masking: Facilitation through increased target-fleld Iuminance and duration'}

DEAN G. PURCELL, University of Toronto, Toronto. Canada, ALAN L. STEWART, Albion College. Albion, Mich. 49224, and WILLIAM N. DEMBER, University of Cincinnati, Cincinnati, Ohio 45221

Studies of visual backward masking demonstrase that increases in target-field luminance or duration will decrease the target's susceptibility to masking. A proposed sheory predicts that, within certain limits. increases in target-field luminance or duration will increase the target's susceptability to masking. Two experiments support these predictions.

The present authors are developing a model of visual backward masking based on the concept of lateral inhibition. The model can handle the phenomenon of target recovery (Dember \& Purcell, 1967; Stewart, Purcell, \& Dember, 1968; Robinson, 1966); it has generated some verifiable predictions relating recovery to the phenomenon of brightness reversal (Purcell \& Dember, 1968), as well as predictions about the effect on masking of spatial properties of the mask (Purcell, Stewart, \& Dember, in press; Sherrick \& Dember, 1968). The present research evaluates the model further by testing the prediction that the detectability of a masked target will decrease, at high levels of target-field luminance, as target-field luminance and target duration increase.

In brief, the pertinent elements of the lateral inhibition concept as applied to our black-disc target, black-ring mask configuration are as follows: A black, or phenomenally dim disc stimulus stimulates little or no firing in relation to the firing provided by its white or phenomenally bright surround. Ratliff (1965) points out that lateral inhibition on a given neuron is a positive function of the rate of firing of neurons adjacent to it, and a negative function of its distance from firing neurons. Thus neurons in the area of the visual system that the disc impinges upon are less inhibited than neurons in the area that the surround impinges upon.
Inhibition persists after the termination of stimulation, but decays over time. While inhibition is present in the visual system, it serves to reduce the rate of neural firing to further visual stimuli. Thus, a stimulus of a given intensity will generate more neural firing in an uninhibited area of the visual system than it will in an inhibited area. Because of the differential in inhibition established by the black-disc, white-surround target presentation, a white masking flash has the effect of setting up a pattern of neural firing which is the reverse of the firing to the target presentation. This reversal may be detected if the $S$ is properly set (Purcell \& Dember. 1968), but under many conditions, including those employed in the present experiments, reversal may also result in backward masking. Research on the compound eye of the Limulus (Ratliff, 1965) demonstrates that the build-up of lateral inhibition is positively related to both stimulus intensity and duration. If these relationships hold for the vertebrate eye, and our application of the lateral inhibition concept to visual backward masking is valid, then we can predict that increasing both the intensity or the duration of the target-field should increase the differential in inhibition between the target disc and its surround, thereby also increasing the amount of backward masking.

\section{METHOD}

Two experiments were run to test these predictions. In the first experiment, 20 naive $S s$ were nun individually in a $1 / 2-h$ long, forced-choice detection experiment designed to test the effect of target-field luminance, with the contrast ratio between the target and its surround held constant. The target presentation consisted of a $3-\mathrm{deg} 4 \mathrm{~min}$ square illuminated white field containing a black target disc $24 \mathrm{~min}$ in diam. The duration of the target presentation was $5 \mathrm{msec}$. Four target-field luminance levels were employed, measured as 30 , 40,50 , and $60 \mathrm{ft}-\mathrm{L}$ by a Spectra brightness spot meter. The contrast ratio between the luminance of the target surround and the target disc was .12 . The masking field contained two 